\title{
Trends in the access to and the use of antipsychotic medications and psychotropic co-treatments in Asian patients with schizophrenia
}

\author{
Y.-T. Xiang ${ }^{1 *}$, G. S. Ungvari' ${ }^{2}$, C. U. Correll ${ }^{3}$, H. F. K. Chiu ${ }^{4}$ and N. Shinfuku ${ }^{5}$ \\ ${ }^{1}$ Unit of Psychiatry, Faculty of Health Sciences, University of Macau, Macao SAR, China \\ ${ }^{2}$ School of Psychiatry \& Clinical Neurosciences, University of Western Australia, Perth, Australia \\ ${ }^{3}$ Division of Psychiatry Research, The Zucker Hillside Hospital, North Shore-Long Island Jewish Health System, Glen Oaks, NY, USA \\ ${ }^{4}$ Department of Psychiatry, Chinese University of Hong Kong, Hong Kong SAR, China \\ ${ }^{5}$ International Centre for Medical Research, Kobe University School of Medicine, Kobe, Japan
}

To date, antipsychotics remain the mainstay of treatment for schizophrenia and related disorders although other psychotropic medications and non-pharmaceutical interventions have been used adjunctively in some patients and settings. Regular surveys on access to and prescription patterns of psychotropic medications in clinical practice are an important and efficient way of examining the use and time trends of treatments in a given population and region. Unlike developed Western countries, Asian countries have not fully undergone deinstitutionalisation of the severely and chronically mentally ill, and community-based mental health services are still under-developed. As a result, a large number of psychiatric patients still receive treatments in psychiatric hospitals. Moreover, there have been very limited studies examining access to and prescription patterns of psychotropic medications for schizophrenia patients in Asian countries. In this paper, we focus on the only international project on the use of psychotropic medications in schizophrenia patients in selected East and Southeast Asian countries/territories summarising its major findings. Most of the first- and second-generation antipsychotics (FGAs and SGAs) are available in Asian countries, but the access to psychotropic medications is largely affected by socio-cultural and historical contexts, health insurance schemes, health care policy, medication cost and consumers' preference across different countries/territories. Overall, the proportional use of FGAs, high dose antipsychotic treatment and antipsychotic polypharmacy have decreased, while the use of SGAs and antidepressants have increased and the utilisation of benzodiazepines and mood stabilisers has remained relatively stable over time. However, within these general trends, there is great inter-country variation regarding the psychotropic prescribing patterns and trends in Asian schizophrenia patients that also seems to differ from data in many Western countries.

First published online 20 August 2015

Key words: Asia, prescription patterns, psychotropic medications, schizophrenia.

\section{Introduction}

Nowadays most treatment guidelines on the use of psychotropic drugs are based on randomised controlled trials. However, significant differences exist between the patients studied in pre-marketing clinical trials and those treated in real-world clinical practice (Martin et al. 2004). In order to improve inter-individual homogeneity, in pre-marketing trials, small samples of patients are usually selected from target populations with stringent study criteria. Generally, psychiatric and relevant medical comorbidities as well as co-medications are excluded, and the focus is on high internal validity, paying the price of reduced

* Address correspondence: Dr Y.-T. Xiang, Faculty of Health Sciences, University of Macau, Avenida da Universidade, 3/F, Building E12, Taipa, Macau SAR, China.

(E-mail: xyutly@gmail.com) generalisability or 'external validity' (Correll et al. 2011). In contrast, in clinical practice, psychiatrists often use medications and medication combinations in ways that have not been studied in either pre- or post-marketing trials. For example, they may prescribe the medication at different doses or to different groups of patients than studied but who have the same disease, may use different treatment combinations, or even target different indications (off-label use).

Antipsychotic medications have been introduced in Asia since the 1950s and soon became the mainstay of treatment for schizophrenia and related disorders. In the past decades, developing community-based mental health services have been encouraged in many Asian societies, but due to many historical, economic and socio-cultural reasons, a large number of psychiatric patients still receive hospital-based services. As a result, the numbers of psychiatric beds in many 
Asian counties have not decreased, or have even been increasing (Shinfuku \& Tan, 2008).

Psychotropic medication utilisation varies greatly across different countries and over time (Rothbard et al. 2003; Bowers et al. 2004). This has to do with different thresholds for illness identification and pharmacologic intervention, availability and acceptability of alternative treatment approaches, levels of stigma and help-seeking, barriers to and availability of care. Thus, it is not surprising that psychotropic medication utilisation also varies greatly in Asia. For example, in Japan high dose antipsychotic use and antipsychotic polypharmacy were common, Singapore had high utilisation of antipsychotic depot injections and in China clozapine was used extensively (Chong et al. 2004). However, cautious interpretation of the observational results is necessary, as medication utilisation primarily depends on the availability of the medication, drug regulatory and health delivery systems, medication cost and coverage and marketing by pharmaceutical companies. In order to rationalise their use, it is important to understand access to, trends and patterns of psychotropic medication use in clinical practice.

Access to and prescription patterns of psychotropic medications have been extensively examined in North America and European countries (Bowers et al. 2004; Huskamp, 2005; Gallego et al. 2012a). In contrast, very limited studies have been performed in Asian countries. To the best of our knowledge, to date only one international, pharmaco-epidemiological project has been conducted in Asia. For the purpose of this paper, we introduce the methodology of this international, pharmaco-epidemiological study and summarise its major findings, which will help put into perspective data from other regions in the world.

\section{The research on Asian psychotropic prescription pattern (REAP) project}

In 1999 an international collaborative research group comprising psychiatrists, pharmacologists and epidemiologists initiated a large-scale longitudinal, observational, pharmaco-epidemiological project entitled the Research on East Asia Psychotropic Prescriptions (REAP) study. The REAP project examined the prescription trends for psychotropic drugs in schizophrenia inpatients in six Asian countries and territories (China, Hong Kong, Japan, Korea, Singapore and Taiwan). The first REAP survey was carried out in July 2001 (REAP-AP1) followed by the second and third surveys in July 2004 (REAP-AP2) and October 2008-March 2009 (REAP-AP3), respectively, using the same design and standardised protocol. India, Malaysia and Thailand joined the REAP project in
REAP-AP3 therefore the project was renamed as Research on Asian Psychotropic Prescription Pattern (REAP).

Prior to each survey, consensus meetings were held to agree upon the procedures of data collection and data entry. The original English version of the data collection forms was translated into the local languages of the participating countries and territories. Patients were diagnosed with schizophrenia according to either DSM-IV or ICD-10 criteria. Psychotropic medications were classified according to the Anatomical Therapeutic Chemical classification by the WHO Collaborating Centre for Drug Statistics Methodology (WHO Collaborating Centre for Drug Statistic Methodology, 2002).

Demographic and clinical characteristics including use of antipsychotics, benzodiazepines antidepressants and mood stabilisers were collected using a data collection form designed for the study. The data were collected based on a review of medical records in 2001 and by either a review of medical records alone or a review supplemented by a clinical interview in 2004 and 2009 in different study sites. Data were collected by the patients' treating psychiatrists or by members of the research team with the agreement of the psychiatrist in- charge of the patient. Each national/territorial coordinating centre was responsible to establish the dataset with a uniform data entry sheet, which were sent to the overall coordinators in Taipei, Taiwan and Kobe, Japan for compilation and statistical analyses.

\section{Mental health resources in Asian countries and territories}

Table 1 shows mental health resources in the countries and territories participating in the REAP study. Of the Asian countries/territories, Japan had the largest number of psychiatric beds and psychiatrists per capita, followed by Korea. In contrast, India and Thailand had the lowest number of psychiatric beds and psychiatrists per capita. Altogether, 31 psychiatric facilities participated in 2001, 25 in 2004 and 50 in 2009 in REAP surveys.

\section{Access to psychotropic medications}

Table 2 following the first antipsychotic medication, chlorpromazine, other first-generation antipsychotics (FGAs) were introduced into Asia between the 1960s and 1980s. second-generation antipsychotics (SGAs) were introduced into Asia since the 1990s, except for clozapine, which was introduced to Asia in the 1970s.

Clozapine was developed by the pharmaceutical company Wander Laboratories in 1959; however, it 
Table 1. Mental health resources in participating countries and territories (World Health Organisation, 2011)

\begin{tabular}{lrrrr}
\hline & Population (1000) & Psychiatrists per 100000 & Psychiatric beds per 10000 & Total psychiatric beds \\
\hline China & 1354146 & 1.5 & 1.5 & 199318 \\
India & 1214464 & 0.3 & 0.2 & 27835 \\
Japan & 126995 & 10.1 & 27.7 & 352437 \\
Thailand & 68139 & 0.4 & 1.3 & 8774 \\
Korea & 48500 & 5.1 & 19.0 & 92382 \\
Malaysia & 27913 & 0.8 & 1.8 & 5106 \\
Taiwan* & 22879 & 3.7 & 7.5 & 1716 \\
Hong Kong & 7069 & 4.4 & 5.1 & 3589 \\
Singapore & 4836 & 2.8 & 4.2 & 2044 \\
\hline
\end{tabular}

*Taiwan was not included in the WHO ATLAS-2011, therefore we listed the data in the WHO ATLAS-2005 (Shinfuku \& Tan, 2008).

was removed from the market in the USA and some European countries later in the 1970s because it can induce potentially fatal agranulocytosis in rare cases (Idanpaan-Heikkila et al. 1975). Due to its unique efficacy in treating refractory schizophrenia (Kane et al. 1988) and the introduction of regular monitoring of white blood cell count to reduce the risk of agranulocytosis, the US Food and Drug Administration (FDA) approved clozapine again in the early 1990s, but restricted its use to patients with treatment resistant to schizophrenia. In contrast, in China clozapine has been widely used even as a first-line treatment since its introduction in 1976 (Liu \& Li, 2003; Xiang et al. $2007 b$ ). In Japan, however, clozapine had not been approved until the end of 2009.

Nowadays, most of FGAs and SGAs are available in Asian countries/territories involved in the REAP surveys. However, patient access and prescribing habits of clinicians in each Asian country are multidetermined. Individual factors include country-level insurance coverage, cost, ease and speed of generics penetrating the market, physician-level incentives if they also function as pharmacists. Some examples in specific countries are detailed in an exemplary fashion below.

The reimbursement and specific license of medications approved by governments plays the decisive role in the availability of psychotropics. For example, there were only four SGAs available in Japan and seven in Taiwan in 2004 when the second REAP survey was carried out (Shinfuku \& Tan, 2008). Some of these differences have to do with whether the local body approving new medications evaluates data collected in different populations and submitted to the USA or European licensing bodies, or whether studies in samples from the specific Asian country are required to concern about significant genetic differences that may translate in clinically relevant pharmaco-kinetic and/or pharmaco-dynamic differences. One example is Japan, when, as mentioned before, clozapine was approved as late as 2009 and where greater restrictions to the use of clozapine exist, such as initiation only during inpatient stay.

In China, clozapine is one of the cheapest antipsychotics, costing only US\$ 0.08 for $300 \mathrm{mg}$. In addition, clozapine and risperidone were the only SGAs covered by public health insurance before 2005. Consequently, clozapine was the most widely used SGA in practice. In addition, competition between imported and locally manufactured products greatly influences the access to psychotropic medications. Locally manufactured, generic psychotropic medications, particularly novel antipsychotics and antidepressants, are usually approved by China FDA and then are introduced into market after or, even before, the patent protection period of their imported counterparts expires. The efficacy and adverse events of locally manufactured psychotropic medications are mostly sufficiently similar to the patented products (Yin et al. 2005; Li et al. 2006), but their price is merely around one third or half of the branded counterparts. Therefore, locally produced generics are more likely preferred by some patients, their families and sometimes even treating psychiatrists, which determines the availability of imported SGAs and antidepressants in many hospitals.

In Japan, all patients receiving psychiatric care are covered by national insurance system. Treatment costs are compensated equally for private and public psychiatric hospitals. In principle, patients need to pay $10 \%$ or $30 \%$ of their treatment costs and the rest is compensated by public funds. However, long stay in private and public psychiatric hospitals could be subsided by the life protection scheme; therefore patient's payments are exempted. This medical compensation system might have contributed to the high dose prescription and polypharmacy in Japan. 
Table 2. Socio-demographic and clinical characteristics and psychotropic drug prescription in Asia in 2001, 2004, and 2009

\begin{tabular}{|c|c|c|c|c|c|c|c|c|c|c|c|c|c|c|c|c|c|c|c|c|c|c|c|c|}
\hline \multirow[b]{2}{*}{ Survey time } & \multicolumn{3}{|c|}{ China } & \multicolumn{3}{|c|}{ Hong Kong } & \multicolumn{3}{|c|}{ Japan } & \multicolumn{3}{|c|}{ Korea } & \multicolumn{3}{|c|}{ Singapore } & \multicolumn{3}{|c|}{ Taiwan } & \multirow{2}{*}{$\frac{\text { India }}{09^{*}}$} & \multirow{2}{*}{$\begin{array}{l}\text { Thailand } \\
09^{*}\end{array}$} & \multirow{2}{*}{$\frac{\text { Malaysia }}{09^{*}}$} & \multicolumn{3}{|c|}{ Total } \\
\hline & $01^{*}$ & $04^{*}$ & $09^{*}$ & $01^{*}$ & $04^{*}$ & $09^{*}$ & $01^{*}$ & $04^{*}$ & $09^{*}$ & $01^{*}$ & $04^{*}$ & $09^{*}$ & $01^{*}$ & $04^{*}$ & $09^{*}$ & $01^{*}$ & $04^{*}$ & $09^{*}$ & & & & $01^{*}$ & $04^{*}$ & $09^{*}$ \\
\hline Patients $(n)$ & 611 & 504 & 409 & 108 & 100 & 100 & 627 & 583 & 514 & 442 & 412 & 284 & 300 & 91 & 100 & 311 & 446 & 499 & 181 & 39 & 100 & 2399 & 2136 & 2226 \\
\hline Men (\%) & 50.9 & 51.8 & 69.7 & 58.3 & 51.0 & 47.0 & 58.4 & 57.6 & 55.6 & 57.0 & 59.7 & 55.6 & 58.7 & 53.8 & 50.0 & 55.6 & 62.8 & 68.9 & 46.4 & 69.2 & 72.0 & 55.9 & 57.3 & 60.6 \\
\hline \multicolumn{25}{|c|}{ CPZeq (mg/d; \%) } \\
\hline$<300$ & 34.9 & 35.7 & 25.2 & 29.6 & 28.0 & 27.0 & 16.9 & 23.8 & 24.7 & 21.0 & 22.1 & 13.7 & 33.7 & 40.7 & 51.0 & 33.1 & 30.9 & 33.1 & 29.3 & 12.8 & 43.0 & 27.0 & 28.7 & 27.5 \\
\hline 300-999 & 57.6 & 56.5 & 63.1 & 53.7 & 68.0 & 61.0 & 51.2 & 57.1 & 56.8 & 54.8 & 58.7 & 60.9 & 49.0 & 46.2 & 42.0 & 56.9 & 58.7 & 56.5 & 67.4 & 71.8 & 52.0 & 54.1 & 57.7 & 58.8 \\
\hline$\geqslant 1000$ & 7.5 & 7.7 & 11.7 & 16.7 & 4.0 & 12.0 & 31.9 & 19.0 & 18.5 & 24.2 & 19.2 & 25.4 & 17.3 & 13.2 & 7.0 & 10.0 & 10.3 & 10.4 & 3.3 & 15.4 & 5.0 & 18.9 & 13.6 & 13.6 \\
\hline FGA $(\%)$ & 47.3 & 35.1 & 24.2 & 49.1 & 26.0 & 24.0 & 87.4 & 66.6 & 52.9 & 72.9 & 66.3 & 46.1 & 84.3 & 81.3 & 49.0 & 52.1 & 38.3 & 37.7 & 30.9 & 82.1 & 78.0 & 67.8 & 51.9 & 41.7 \\
\hline SGA (\%) & 64.0 & 75.6 & 83.9 & 46.3 & 68.0 & 50.0 & 50.4 & 75.6 & 85.0 & 37.1 & 45.9 & 75.0 & 6.7 & 16.5 & 50.0 & 48.6 & 64.6 & 73.5 & 80.7 & 30.8 & 23.0 & 45.5 & 64.7 & 73.7 \\
\hline $\operatorname{APP}(\%)$ & 25.2 & 23.8 & 35.9 & 35.2 & 24.0 & 23.0 & 78.6 & 67.1 & 60.9 & 35.5 & 37.6 & 44.4 & 70.3 & 75.8 & 74.0 & 22.2 & 13.2 & 26.9 & 45.9 & 64.1 & 41.0 & 46.8 & 38.3 & 43.4 \\
\hline BZD & 7.2 & 24.8 & 16.6 & 23.1 & 40.0 & 26.0 & 22.5 & 25.4 & 21.8 & 49.3 & 25.5 & 50.0 & 51.3 & 80.2 & 47.0 & 27.7 & 25.3 & 27.7 & 37.6 & 7.7 & 52.0 & 27.8 & 28.3 & 29.5 \\
\hline MS & 24.9 & 23.2 & 30.6 & 31.5 & 40.0 & 32.0 & 35.6 & 36.7 & 37.0 & 25.6 & 21.8 & 38.7 & 31.0 & 27.5 & 28.0 & 37.3 & 33.4 & 36.1 & 10.5 & 35.9 & 16.0 & 30.5 & 29.7 & 32.1 \\
\hline $\mathrm{AD}$ & 4.7 & 5.8 & 8.1 & 0.9 & 14.0 & 8.0 & 2.2 & 2.2 & 2.7 & 3.4 & 1.9 & 10.9 & 15.3 & 15.4 & 22.0 & 7.4 & 13.7 & 13.2 & 5.0 & 7.7 & 7.0 & 5.3 & 6.5 & 8.7 \\
\hline
\end{tabular}

$\mathrm{AD}$, antidepressant; APP, antipsychotic polypharmacy (more than 1 antipsychotic medication); BZD, benzodiazepine; CPZeq, chlorpromazine equivalents; EPS, extrapyramidal symptoms; FGA, first-generation antipsychotic; MS, mood stabiliser; SGA, second-generation antipsychotic.

Mood stabilisers include valproate, lithium, carbamazepine, phenobarbital, phenytoin, lamotrigine, topiramate and zonisamide.

Centres in India, Malaysia and Thailand joined the survey in 2009.

${ }^{*} 01=2001,04=2004,09=2009$. 
In Singapore, on the other hand, the more common use of depot antipsychotics in public psychiatric hospitals is encouraged due to treatment cost containment and less artificial separation between the medication budget and the budget paying for expensive hospitalisations. Conversely, the very low use of depot antipsychotics in China that has been reported to be $2.8 \%$ only ( $\mathrm{Si}, 2014)$, is due to the fact that depot medications, especially SGA injectables are not yet covered by the government and will need to be paid by patients and families.

\section{Prescription trends of FGAs and SGAs}

SGAs have significant advantages over FGAs in reducing all-cause discontinuation, improving (or less worsening of) negative symptoms and global cognition and causing less extrapyramidal symptoms, although they may increase the risk of metabolic syndrome (Zhang et al. 2013). However, we found in the REAP surveys that although the prescribing rates of FGAs decreased over time $(67.8 \%$ in $2001,51.9 \%$ in 2004 and $41.7 \%$ in 2009), there were still approximately half of patients in the participating Asian countries receiving FGAs in the whole sample. The underlying reasons behind this unexpected finding cannot be examined with confidence based on the current crosssectional design. Nevertheless, we speculate that socio-economic and cultural factors including psychopharmacological traditions, prior antipsychotic treatment, uneven access to different antipsychotics, higher cost of SGAs and insurance and health policy restrictions may determine the ongoing frequent use of FGAs in Asian schizophrenia patients (Xiang et al. $2012 b$ ). However, a recent network meta-analysis of 212 acute phase studies of antipsychotics in patients with schizophrenia (Leucht et al. 2013) showed that individual antipsychotics differed substantially in efficacy and side-effects, challenging the crude classification of antipsychotics into FGAs and SGAs, which are both heterogeneous. Therefore the choice of antipsychotics should depend on the needs of individual patients and take prior therapeutic and adverse effect patterns, access and affordability all into account. Table 3 shows the most commonly prescribed antipsychotic drugs.

\section{Use of high dose antipsychotics}

The use of high antipsychotic doses has been controversial in clinical practice. Most treatment recommendations do not recommend high antipsychotic doses (Buchanan et al. 2010; Kreyenbuhl et al. 2010). Studies failed to find convincing evidence for improved
Table 3. The most commonly prescribed antipsychotic drugs and antidepressants in Asia in 2001, 2004 and 2009

\begin{tabular}{|c|c|c|c|c|c|c|}
\hline & \multicolumn{2}{|c|}{2001} & \multicolumn{2}{|c|}{2004} & \multicolumn{2}{|c|}{2009} \\
\hline & $n$ & $\%$ & $n$ & $\%$ & $n$ & $\%$ \\
\hline \multicolumn{7}{|l|}{ FGAs } \\
\hline Haloperidol & 690 & 28.8 & 387 & 18.1 & 412 & 18.5 \\
\hline Chlorpromazine & 561 & 23.4 & 349 & 16.3 & 251 & 11.3 \\
\hline Sulpiride & 232 & 9.7 & 178 & 8.3 & 129 & 5.8 \\
\hline Fluphenzine decanoate & 112 & 4.7 & 38 & 1.8 & 66 & 3.0 \\
\hline Flupentixol decanoate & 95 & 4.0 & 52 & 2.4 & 85 & 3.8 \\
\hline \multicolumn{7}{|l|}{ SGAs } \\
\hline Risperidone & 472 & 19.7 & 631 & 29.5 & 689 & 31.0 \\
\hline Clozapine & 348 & 14.5 & 340 & 15.9 & 331 & 14.9 \\
\hline Olanzapine & 114 & 4.8 & 226 & 10.6 & 352 & 15.8 \\
\hline Quetiapine & 86 & 3.6 & 167 & 7.8 & 226 & 10.2 \\
\hline Aripiprazole & 0 & 0 & 0 & 0 & 113 & 5.1 \\
\hline \multicolumn{7}{|l|}{ Antidepressants } \\
\hline Fluoxetine & 28 & 1.2 & 27 & 1.3 & 27 & 1.2 \\
\hline Fluvoxamine & 14 & 0.6 & 17 & 0.8 & 40 & 1.8 \\
\hline Trazodone & 12 & 0.5 & 38 & 1.8 & 34 & 1.5 \\
\hline Paroxetine & 8 & 0.3 & 17 & 0.8 & 11 & 0.5 \\
\hline Sertraline & 5 & 0.2 & 9 & 0.4 & 30 & 1.3 \\
\hline
\end{tabular}

$\%$, percentage of all patients; FGA, first-generation antipsychotic; SGA, second-generation antipsychotic.

efficacy with high antipsychotic doses, but the risk of extrapyramidal side effects (Pierre, 2005) and hyperprolactinemia (Byerly et al. 2007) was dose-related. The percentage of high dose antipsychotics of $15.5 \%$ across the three REAP survey time points (2001: 18.9\%, 2004: 13.6\%, 2009: 13.6\%) depends on treatment settings and populations, but is in the lower range compared with Western findings of $15.4-41 \%$ (Webb \& Agnew, 1975; Buchanan et al. 2010; Kreyenbuhl et al. 2010). The percentage of high antipsychotic doses was particularly prominent in Japan. Based on the current study design we cannot identify the reasons for the common use of high antipsychotic doses in Japan, except for assuming that probably clinical traditions might play an important role. In addition, it was reported that sometimes sedation was the primary purpose of pharmacotherapy for schizophrenia inpatients in Japan (Fujii \& Shinfuku, 2005; Shinfuku \& Tan, 2008), which may partly also explain the common use of high antipsychotic doses.

Use of high antipsychotic doses significantly decreased over time in Asian patients, which is mainly driven by changes in Japan. It was reported that the presentations at academic meetings and relevant publications about the findings based on REAP surveys may have enhanced Japanese clinicians' awareness of rational prescription practices (Shinfuku \& Tan, 2008). 


\section{Antipsychotic polypharmacy}

Although two meta-analyses suggested that antipsychotic polypharmacy may have superior efficacy compared with antipsychotic monopharmacy (Barbui et al. 2009; Correll et al. 2009), results were inconclusive. The reason that antipsychotic polypharmacy could not be recommended was that in both meta-analyses, data were relatively scare, a publication bias could not be excluded and certain moderators of the efficacy lowered the level of the evidence. While, antipsychotic polypharmacy is associated with the potential for increased hospitalisation rates, increased side effects and higher treatment cost and increased mortality (Elie et al. 2010; Tiihonen et al. 2012; Gallego et al. 2012b). Based on these findings, several attempts have been made to reduce antipsychotic polypharmacy in clinical practice settings (Essock et al. 2011; Tani et al. 2013).

The frequency of antipsychotic polypharmacy of $43 \%$ found in the whole REAP sample across the three surveys is higher than the frequencies found pooled analysis from 147 studies across four decades, finding pooled antipsychotic polypharmacy frequencies of $16 \%$ in North America and $23 \%$ in Europe (Gallego et al. 2012a). However, the REAP project showed a slight decrease in the use of antipsychotic polypharmacy in schizophrenia inpatients in Asia from $46.8 \%$ in 2001 to $38.3 \%$ in 2004 , and $43.4 \%$ in 2009 (Xiang et al. 2012c).

\section{Adjunctive antidepressant prescriptions}

Depressive symptoms are common in schizophrenia leading to potentially serious consequences (Conley, 2009). Therefore, antidepressants are not infrequently co-prescribed with antipsychotics, although the rationale for this strategy is still controversial (Himelhoch et al. 2012). In the REAP surveys only a small proportion of patients $(6.8 \%$ in the pooled sample) received antidepressant treatment with increasing frequency from $5.3 \%$ in 2001 to $6.5 \%$ in 2004 , and to $8.7 \%$ in 2009. This slight increase might possibly be explained by the introduction and widespread use of novel antidepressants that are generally better tolerated than tricyclic antidepressants.

The frequency of antidepressant prescriptions in Asian schizophrenia patients is significantly lower than the figures in Western patients. The Clinical Trials of Intervention Effectiveness study in the USA found that $38 \%$ of patients received at least one antidepressant (Chakos et al. 2006). Himelhoch et al. (Himelhoch et al. 2012) reported that $37.4 \%$ of outpatient veterans with schizophrenia received an antidepressant prescription in the USA. One possible reason for this difference in anti-depressant prescribing for patients with schizophrenia may be a different level of awareness of comorbid depression in schizophrenia between Asian and Western settings (Xiang et al. 2013). Another reason for this difference may lie in the fact that the utility of antidepressants for negative symptoms, demonstrated in several meta-analyses (Rummel et al. 2006; Sepehry et al. 2007; Singh et al. 2010; Hecht \& Landy, 2012), may either be interpreted differently, or that negative symptoms are considered less as a viable treatment target in Asia. Finally, the low rate of antidepressant use in Asian patients may be due to the lack of compelling evidence for the usefulness of antidepressant use in schizophrenia in general (Himelhoch et al. 2012). Table 3 presents the most commonly prescribed antidepressants.

\section{Adjunctive mood stabiliser and benzodiazepine prescriptions}

Mood stabilisers and benzodiazepines are commonly used as adjunctive medications with antipsychotic treatment in schizophrenia. The rationale behind this practice is that mood stabilisers may help control aggression and irritability and augment antipsychotics (Citrome, 1995) for patients who do not, or only partially respond to antipsychotic monotherapy (Parepally et al. 2002). Benzodiazepines are prescribed primarily for anxiety, insomnia and as part of rapid tranquillisation aiming to control psychotic symptoms and agitation (Xiang et al. 2007a; Tor et al. 2011). However, there is lack of compelling evidence to support these adjunctive medications (Citrome et al. 2000; Chen et al. 2007; Buchanan et al. 2010). Conversely, concurrent use of antipsychotics, mood stabilisers and benzodiazepines may increase the risk of additional side effects, the cost of treatment and reduce treatment adherence (Parepally et al. 2002).

In the whole sample of the three REAP surveys, 30.8 and $28.5 \%$ of patients received mood stabilisers and benzodiazepines, respectively. These rates were higher than reported in the literature. For example, in Australia $10.6 \%$ of schizophrenia patients received mood stabilisers (Castle et al. 2002). In a study covering ten European countries, $7-19 \%$ of schizophrenia patients received mood stabilisers (Haro \& SalvadorCarulla, 2006). The common use of mood stabilisers and benzodiazepines in Asian countries may be due to the following reasons. REAP surveys involved only hospitalised patients who were more likely to suffer from more mood disturbance and symptoms of violence or agitation. Further, concerns about withdrawal effects and deterioration of the mental state following the cessation of mood stabilisers and benzodiazepines may prevent psychiatrists from discontinuing these 
drugs (Ungvari et al. 1997; Xiang et al. 2012a). Moreover, in Asia there is a traditional medical belief that the combination of medications with different pharmacological properties is more effective despite the lack of compelling evidence for this practice (Binder et al. 1987). In this context, it should be noted that neither mood stabilisers nor benzodiazepines have been approved by the US FDA for the treatment of schizophrenia (Pickar et al. 2008).

\section{Concluding comments}

The comparison of the three completed REAP surveys may approximate trends in the prescription patterns of psychotropics for schizophrenia inpatients in Asia. However, because the study sample comprised only hospitalised patients in nine Asian countries and territories and in selected institutions in these countries and territories, the results cannot be generalised to all schizophrenia populations in Asia. More Asian countries should be included in future REAP surveys or similar projects. In addition, some important variables, such as prior psychotropic treatment, treatment targets and duration and treatment response and adverse effects, were not recorded in the REAP surveys. Finally, the REAP surveys did not cover West Asia.

Nevertheless, the results of the REAP survey indicate that access to and prescription patterns of psychotropic medications for patients with schizophrenia in Asia differ considerably across countries and territories and over time, and are still considerably different from those reported in Western settings. The rationale and appropriateness of these prescription patterns need to be examined further. In future surveys in Asia and elsewhere, it should be attempted to add data that capture the rationale for and outcome of certain treatment practices, include data on adherence patterns and patient-centred outcomes, such as treatment satisfaction and quality of life, and/or link survey data to registries that capture hospitalisation and mortality data at a minimum.

\section{Acknowledgement}

None.

\section{Financial Support}

This research received no specific grant from any funding agency, commercial or not-for-profit sectors.

\section{Conflict of Interest}

Dr Correll has been a consultant and/or advisor to or has received honoraria from: AbbVie, Actavis, Actelion, Alexza; Alkermes, Bristol-Myers Squibb, Cephalon, Eli
Lilly, Genentech, Gerson Lehrman Group, IntraCellular Therapies, Janssen/J\&J, Lundbeck, Medavante, Medscape, Merck, Otsuka, Pfizer, ProPhase, Reviva, Roche, Sunovion, Supernus, Takeda, Teva, and Vanda. He has received grant support from Bristol-Myers Squibb, Janssen/J\&J, Novo Nordisk A/S, Otsuka and Takeda.

\section{References}

Barbui C, Signoretti A, Mule S, Boso M, Cipriani A (2009). Does the addition of a second antipsychotic drug improve clozapine treatment? Schizophrenia Bulletin 35, 458-468.

Binder RL, Kazamatsuri H, Nishimura T, McNiel DE (1987). Tardive dyskinesia and neuroleptic-induced parkinsonism in Japan. American Journal of Psychiatry 144, 1494-1496.

Bowers L, Callaghan P, Clark N, Evers C (2004). Comparisons of psychotropic drug prescribing patterns in acute psychiatric wards across Europe. European Journal of Clinical Pharmacology 60, 29-35.

Buchanan RW, Kreyenbuhl J, Kelly DL, Noel JM, Boggs DL, Fischer BA, Himelhoch S, Fang B, Peterson E, Aquino PR, Keller W (2010). The 2009 schizophrenia PORT psycho-pharmacological treatment recommendations and summary statements. Schizophrenia Bulletin 36, 71-93.

Byerly M, Suppes T, Tran QV, Baker RA (2007). Clinical implications of antipsychotic-induced hyperprolactinemia in patients with schizophrenia spectrum or bipolar spectrum disorders: recent developments and current perspectives. Journal of Clinical Psychopharmacology 27, 639-661.

Castle D, Morgan V, Jablensky A (2002). Antipsychotic use in Australia: the patients' perspective. Australian and New Zealand Journal of Psychiatry 36, 633-641.

Chakos MH, Glick ID, Miller AL, Hamner MB, Miller DD, Patel JK, Tapp A, Keefe RS, Rosenheck RA (2006). Baseline use of concomitant psychotropic medications to treat schizophrenia in the CATIE trial. Psychiatric Services 57, 1094-1101.

Chen H, Kennedy WK, Dorfman JH, Fincham JE, Reeves J, Martin BC (2007). The effect of adjunctive mood stabilizers on antipsychotic utilization pattern and health resource utilization for Medicaid enrollees with schizophrenia. Current Medical Research and Opinion 23, 1351-1365.

Chong MY, Tan CH, Fujii S, Yang SY, Ungvari GS, Si T, Chung EK, Sim K, Tsang HY, Shinfuku N (2004). Antipsychotic drug prescription for schizophrenia in East Asia: rationale for change. Psychiatry and Clinical Neurosciences 58, 61-67.

Citrome L (1995). Use of lithium, carbamazepine, and valproic acid in a state-operated psychiatric hospital. Journal of Pharmacy Technology 11, 55-59.

Citrome L, Levine J, Allingham B (2000). Changes in use of valproate and other mood stabilizers for patients with schizophrenia from 1994 to 1998. Psychiatric Services 51, 634-638.

Conley RR (2009). The burden of depressive symptoms in people with schizophrenia. Psychiatric Clinics of North America 32, 853-861. 
Correll CU, Rummel-Kluge C, Corves C, Kane JM, Leucht S (2009). Antipsychotic combinations vs monotherapy in schizophrenia: a meta-analysis of randomized controlled trials. Schizophrenia Bulletin 35, 443-457.

Correll CU, Kishimoto T, Kane JM (2011). Randomized controlled trials in schizophrenia: opportunities, limitations, and trial design alternatives. Dialogues in Clinical NeuroSciences 13, 155-172.

Elie D, Poirier M, Chianetta J, Durand M, Gregoire C, Grignon S (2010). Cognitive effects of antipsychotic dosage and polypharmacy: a study with the BACS in patients with schizophrenia and schizoaffective disorder. Journal of Psychopharmacology 24, 1037-1044.

Essock SM, Schooler NR, Stroup TS, McEvoy JP, Rojas I, Jackson C, Covell NH (2011). Effectiveness of switching from antipsychotic polypharmacy to monotherapy. American Journal of Psychiatry 168, 702-708.

Fujii S, Shinfuku N (2005). Utilization of levomepromazine in Japan - Its role as an antipsychotic in psychiatric pharmacotherapy (In Japanese). Rinsyo Seisin Yakuri 8, 1227-1238.

Gallego JA, Bonetti J, Zhang J, Kane JM, Correll CU (2012a). Prevalence and correlates of antipsychotic polypharmacy: a systematic review and meta-regression of global and regional trends from the 1970 s to 2009. Schizophrenia Research 138, 18-28.

Gallego JA, Nielsen J, De Hert M, Kane JM, Correll CU $(2012 b)$. Safety and tolerability of antipsychotic polypharmacy. Expert Opinion on Drug Safety 11, 527-542.

Haro JM, Salvador-Carulla L (2006). The SOHO (Schizophrenia Outpatient Health Outcome) study: implications for the treatment of schizophrenia. CNS Drugs 20, 293-301.

Hecht EM, Landy DC (2012). Alpha-2 receptor antagonist add-on therapy in the treatment of schizophrenia; a meta-analysis. Schizophrenia Research 134, 202-206.

Himelhoch S, Slade E, Kreyenbuhl J, Medoff D, Brown C, Dixon L (2012). Antidepressant prescribing patterns among VA patients with schizophrenia. Schizophrenia Research, doi:10.1016/j.schres.2012.1001.1008.

Huskamp HA (2005). Pharmaceutical cost management and access to psychotropic drugs: the US context. International Journal of Law and Psychiatry 28, 484-495.

Idanpaan-Heikkila J, Alhava E, Olkinuora M, Palva I (1975). Letter: clozapine and agranulocytosis. Lancet 2, 611.

Kane J, Honigfeld G, Singer J, Meltzer H (1988). Clozapine for the treatment-resistant schizophrenic. A double-blind comparison with chlorpromazine. Archives of General Psychiatry 45, 789-796.

Kreyenbuhl J, Buchanan RW, Dickerson FB, Dixon LB (2010). The schizophrenia Patient Outcomes Research Team (PORT): updated treatment recommendations 2009. Schizophrenia Bulletin 36, 94-103.

Leucht S, Cipriani A, Spineli L, Mavridis D, Orey D, Richter F, Samara M, Barbui C, Engel RR, Geddes JR, Kissling W, Stapf MP, Lassig B, Salanti G, Davis JM (2013). Comparative efficacy and tolerability of 15 antipsychotic drugs in schizophrenia: a multiple-treatments meta-analysis. Lancet 382, 951-962.
Li LH, Zhao JP, Xu XF, Meng QH, Ning J (2006). A comparative study of locally manufactured intramuscular ziprasidone and haloperidol in treating acute atitation in schizophrenia (in Chinese). Chinese Journal of Psychiatry 39, 216-219.

Liu TL, Li CY (2003). The comparison of use of antipsychotics in first-episode patients with schizophrenia (in Chinese). Medical journal of Chinese people Health 15, 289-290.

Martin K, Begaud B, Latry P, Miremont-Salame G, Fourrier A, Moore N (2004). Differences between clinical trials and post-marketing use. British Journal of Clinical Pharmacology 57, 86-92.

Parepally H, Chakravorty S, Levine J, Brar JS, Patel AM, Baird JW, Chalasani L, Delaney JA, Atzert R, Chengappa KN (2002). The use of concomitant medications in psychiatric inpatients treated with either olanzapine or other antipsychotic agents: a naturalistic study at a state psychiatric hospital. Progress in Neuro-Psychopharmacology and Biological Psychiatry 26, 437-440.

Pickar D, Vinik J, Bartko JJ (2008). Pharmacotherapy of schizophrenic patients: preponderance of off-label drug use. PLoS ONE 3, e3150.

Pierre JM (2005). Extrapyramidal symptoms with atypical antipsychotics: incidence, prevention and management. Drug Safety 28, 191-208.

Rothbard AB, Kuno E, Foley K (2003). Trends in the rate and type of antipsychotic medications prescribed to persons with schizophrenia. Schizophrenia Bulletin 29, 531-540.

Rummel C, Kissling W, Leucht S (2006). Antidepressants for the negative symptoms of schizophrenia. Cochrane Database of Systematic Reviews 3, CD005581.

Sepehry AA, Potvin S, Elie R, Stip E (2007). Selective serotonin reuptake inhibitor (SSRI) add-on therapy for the negative symptoms of schizophrenia: a meta-analysis. Journal of Clinical Psychiatry 68, 604-610.

Shinfuku N, Tan CH (2008). Pharmacotherapy for schizophrenic inpatients in East Asia--changes and challenges. International Review of Psychiatry 20, 460-468.

Si TM (2014). The Third Survey of Prescription Pattern of Psychotropic Drugs in China: Schizophrenia Patients Prescription Status. In The Chinese Society of Neuroscience \& Psychiatry Annual Meeting, Nanchang.

Singh SP, Singh V, Kar N, Chan K (2010). Efficacy of antidepressants in treating the negative symptoms of chronic schizophrenia: meta-analysis. British Journal of Psychiatry 197, 174-179.

Tani H, Uchida H, Suzuki T, Fujii Y, Mimura M (2013). Interventions to reduce antipsychotic polypharmacy: a systematic review. Schizophrenia Research 143, 215-220.

Tiihonen J, Suokas JT, Suvisaari JM, Haukka J, Korhonen P (2012). Polypharmacy with antipsychotics, antidepressants, or benzodiazepines and mortality in schizophrenia. Archives of General Psychiatry 69, 476-483.

Tor PC, Ng TP, Yong KH, Sim K, Xiang YT, Wang CY, Lee EH, Fujii S, Yang SY, Chong MY, Ungvari GS, Si T, He YL, Chung EK, Chee KY, Trivedi J, Udomratn P, Shinfuku N, Kua EH, Tan CH, Sartorius N, Baldessarini RJ (2011). Adjunctive benzodiazepine treatment of hospitalized schizophrenia patients in Asia from 2001 to 
2008. International Journal of Neuropsychopharmacology 14, 735-745.

Ungvari GS, Chow LY, Chiu HF, Ng FS, Leung T (1997). Modifying psychotropic drug prescription patterns: a follow-up survey. Psychiatry and Clinical Neurosciences 51, 309-314.

Webb WB, Agnew HW (1975). Are we chronically sleep deprived? Bulletin of the Psychonomic Society 6, 47-48.

WHO Collaborating Centre for Drug Statistic Methodology (2002). Guidelines for ATC Index with DDDs. WHO: Oslo.

World Health Organization (2011). Mental Health Atlas - 2011 Country Profiles. WHO: Geneva, Switzerland.

Xiang YT, Weng YZ, Leung CM, Tang WK, Ungvari GS (2007a). Clinical and social determinants of long-term use of benzodiazepines and its impact on quality of life of Chinese schizophrenia patients. Pharmacopsychiatry 40, 269-274.

Xiang YT, Weng YZ, Leung CM, Tang WK, Ungvari GS (2007b). Clinical correlates of clozapine prescription for schizophrenia in China. Human Psychopharmacology 22, $17-25$.

Xiang YT, Dickerson F, Kreyenbuhl J, Ungvari GS, Wang CY, Si TM, Lee EH, He YL, Chiu HF, Yang SY, Chong MY, Tan CH, Kua EH, Fujii S, Sim K, Yong MK, Trivedi JK, Chung EK, Udomratn P, Chee KY, Sartorius N, Shinfuku N (2012a). Adjunctive mood stabilizer and benzodiazepine use in older Asian patients with schizophrenia, 2001-2009. Pharmacopsychiatry 45, 217-222.

Xiang YT, Kreyenbuhl J, Dickerson FB, Ungvari GS, Wang CY, Si TM, Lee EH, He YL, Chiu HF, Yang SY, Chong MY,
Tan CH, Kua EH, Fujii S, Sim K, Yong MK, Trivedi JK, Chung EK, Udomratn P, Chee KY, Sartorius N, Shinfuku $\mathbf{N}(2012 b)$. Use of first- and second-generation antipsychotic medications in older patients with schizophrenia in Asia (2001-2009). Australian and New Zealand Journal of Psychiatry 46, 1159-1164.

Xiang YT, Wang CY, Si TM, Lee EH, He YL, Ungvari GS, Chiu HF, Yang SY, Chong MY, Tan CH, Kua EH, Fujii S, Sim K, Yong KH, Trivedi JK, Chung EK, Udomratn P, Chee KY, Sartorius N, Shinfuku N (2012c). Antipsychotic polypharmacy in inpatients with schizophrenia in Asia (2001-2009). Pharmacopsychiatry 45, 7-12.

Xiang YT, Ungvari GS, Wang CY, Si TM, Lee EH, Chiu HF, Lai KY, He YL, Yang SY, Chong MY, Tan CH, Kua EH, Fujii S, Sim K, Yong MK, Trivedi JK, Chung EK, Udomratn P, Chee KY, Sartorius N, Shinfuku N (2013). Adjunctive antidepressant prescriptions for hospitalized patients with schizophrenia in Asia (2001-2009). Asia-Pacific Psychiatry 5, E81-E87.

Yin HR, Huang RH, Chen X, Zhang LR (2005). The effect of locally manufactured aripiprazole in treatment of first episode schizophrenia (in Chinese). Journal of Clinical Research 22, 1000-1001.

Zhang JP, Gallego JA, Robinson DG, Malhotra AK, Kane JM, Correll CU (2013). Efficacy and safety of individual second-generation vs. first-generation antipsychotics in first-episode psychosis: a systematic review and meta-analysis. International Journal of Neuropsychopharmacology 16, 1205-1218. 